\title{
Corrigendum
}

\section{Using a developmental perspective to examine the moderating effects of marriage on heavy episodic drinking in a young adult sample enriched for risk - CORRIGENDUM}

\author{
Seung Bin Cho, Rebecca L. Smith, Kathleen Bucholz, Grace Chan, Howard J. Edenberg, Victor Hesselbrock, \\ John Kramer, Vivia V. McCutcheon, John Nurnberger, Marc Schuckit, Yong Zang, Danielle M. Dick \\ and Jessica E. Salvatore
}

doi: https://doi.org/10.1017/S0954579420000371. Published online by Cambridge University Press 2 July 2020; First Published online 22 September 2021

Keywords: alcohol, development, genetics, marital status, young adults

In the original version of Cho et al. 2020, details about a research grant from Pusan National University were missing from the acknowledgements. They are as follows:

This work was supported by Pusan National University Research Grant, 2018.
The original article has been updated.

\section{Reference}

Cho, S. B., Smith, R. L., Bucholz, K., Chan, G., Edenberg, H. J., Hesselbrock, V., ... Salvatore, J. E. (2021). Using a developmental perspective to examine the moderating effects of marriage on heavy episodic drinking in a young adult sample enriched for risk. Development and Psychopathology, 33(3), 10971106. doi:10.1017/S0954579420000371 